\title{
Analysis of Factors which Affecting Perceived Enjoyment and Customer Continuance Intention onMobile Games Users
}

\author{
Rolando Gultom \\ Department of Industrial Engineering \\ University of Indonesia \\ Depok, Indonesia \\ gultomrolando@gmail.com \\ Ramadhan Khafri \\ Department of Industrial Engineering \\ University of Indonesia \\ Depok, Indonesia \\ khafri.ramadhan26@gmail.com
}

\author{
Boy Nurtjahyo Moch. \\ Department of Industrial Engineering \\ University of Indonesia \\ Depok, Indonesia \\ boymoch@eng.ui.ac.id
}

\author{
Maya Arlini Puspasari \\ Department of Industrial Engineering \\ University of Indonesia \\ Depok, Indonesia \\ maya@ie.ui.ac.id
}

\begin{abstract}
Nowadays utilization of mobile applications, especially for mobile games growth rapidly. This situation affects mobile games market more competitive and results in only few games can survive. The abundance number of mobile games that available makes users will remove their downloaded games if it lacks of interesting experience that affected their enjoyment on first try. Because of this, perceived enjoyment is often considered as an important factor that affects users' intention to continue playing the mobile games. Therefore, this study aims to discover what factors affects perceived enjoyment and find out whether perceived enjoyment is affecting user's intention to continue playing mobile games or not. The research model adopts several latent variables that are used to measure the perceived enjoyment and its effect on continuance intention of mobile games. The model is tested by using Partial Least SquareStructural Equation Modeling (PLS-SEM) with a sample size of 205 respondents.
\end{abstract}

Keywords - Mobile Games, Technology Adoption Modeling, Perceived Enjoyment, Continuance Intention, Partial Least Square - Structural Equation Modeling.

\section{INTRODUCTION}

Lately the technology of information and communication is growing rapidly and becomes a part in the life of modern society today. This situation affected mobile devices such as smartphones and tablet computers are also growing to become the most commonly used goods by the society. In Indonesia, the number of smartphone users are 86.6 million in 2017 and are expected to continue growing up to 103 million users in 2018 [1].

These growth are followed by the growth of mobile application (mobile apps) which designed to facilitate the mobile devices users to perform their activities [2]. Referring to GfK Indonesia's research, mobile apps are uses by the mobile devices users more than browser with $97 \%$ for mobile apps and $76 \%$ for browser usage. Moreover, a research that conducted by Baidu involving more than 2200 respondents in Jakarta, Bogor, Bekasi, Tangerang, Bandung and Surabaya found that most frequently downloaded mobiles apps are games as much $38 \%$, followed by $27 \%$ for text messaging, $19 \%$ for social media, $8 \%$ for online shop apps (including marketplace), $6 \%$ for online transportation service and 3\% for navigation apps and news apps [3]. In May 2016, there are 48,231 apps released by iOS App Store where 20,958 (about $43 \%$ ) are mobile games [4].

From various factors that affected the growth of mobile apps, mobile games are the most factor that contribute the growth of mobile devices. Furthermore, according to Statista research in 2017, mobile games are ranked first in the global games industry by contributing $32 \%$ of total revenue from all devices games, followed by console games by $31 \%$, PC games by $23 \%$ and other devices by $14 \%$ [5].

According to Newzoo's research in 2017, the revenue of games industry amounted to US\$ 108.9 billion in global and estimated to raise where mobile games dominate by $42 \%$ of the total revenue of the global games industry which Asia - Pacific are the region that contributes the most revenue to this industry, where China is the country that most contributed to global games industry with US\$27.5 billion. Newzoo also noted that this growth is expected to continue every year where the Asia (without China, Japan and South Korea) will become the fastest growing region [6]. Based on this data, a great opportunity for apps developer especially mobile games is open widely.

Indonesia became the country with the fastest growing game market in Southeast Asia region. This situation makes Indonesia the most potential target for developers of mobile apps, especially mobile games. In addition, Indonesia also has three times greater potential for advertisers in mobile games 
with number of transactions made by users are $84 \%$ greater than users also has of mobile games in India [7]. Newzoo's research also found that Indonesia already contribute for half of total revenue in the games market with a revenue of US\$ 1.4 billion in Southeast Asia region [6]. It is because Indonesia have 30.7 million active gamers where average spend of their transactions are US\$ 0.4 to US\$ 1.7. Indonesia gamers itself is relatively young where $82 \%$ are under 24 years old and $10 \%$ are between 25 years to 34 years old with average time using mobile games are about 60 minutes per day [3].

However, the competition in the games industry especially in mobile games is very tight and competitive where there are only a few games that managed to produce high number of downloads and can survive in the market while other mobile games are fail [8]. By the abundance of the number and types of mobile games, users of these mobile games will stop playing in their first trial in using mobile games if they lack exciting and interesting experience [9], especially for free-to-play mobile games that most of the revenue mainly from advertising or from a small number of active users willing to pay for some additional features. This results in a low retention rate of mobile games. Yet, what makes continued use an enjoyable to experience is not well understood, neither in computer usage in general, nor in the more specific context of mobile gaming. Though the key to the success of mobile games lies in game players' retention [10]. Therefore it is important for the developers of mobile games to find out what factors affect the users to keep playing their mobile games.

The model of this research has adopted from Merikivi et al (2017) combined with research model of Chen et al (2016) for social factors [11], [12]. To address the research gaps, we will investigate the factors that influence perceived enjoyment and to know whether perceived enjoyment affects continuance intention of user in playing mobile games. The two research questions are accordingly as follows:

1. What factors influence perceived enjoyment in mobile gaming?

2. Is perceived enjoyment influence users to continue using mobile games?

\section{METHOD}

\section{A. Research Model and Research Method}

This study adopted model from two previous research which is a research from Merikivi et al. (2017) for playability attributes and game design attributes and from Chen et al. (2016) for social factors attributes to measure perceived enjoyment variables [11], [12]. There are two latent variables from playability factors that is perceived ease of use and interactivity. From game design factors there are four latent variables which is challenge, variety, novelty and design aesthetic. Last, social factors have two latent variables which is shared identity and social interaction. These factors has been selected because all of them are essential part of mobile games. The research model can be seen from Figure 1.

We use Partial Least Square Structural Equation Modeling (PLS SEM) method. PLS SEM was used to build theory in explorative research. Partial least square (PLS) is a method for constructing a model when there are many factors with high collinearity. PLS-SEM estimates coefficients that maximize $\mathrm{R}^{2}$ values from endogenous latentvariables [13].

\section{B. Research Hypothesis}

\section{1) Playability Attributes}

\section{a) Perceived Ease of Use}

Perceived ease of use (PEOU) is defined as the degree of a person believes in using a particular system will be free from excessive effort [14]. The relationship between.

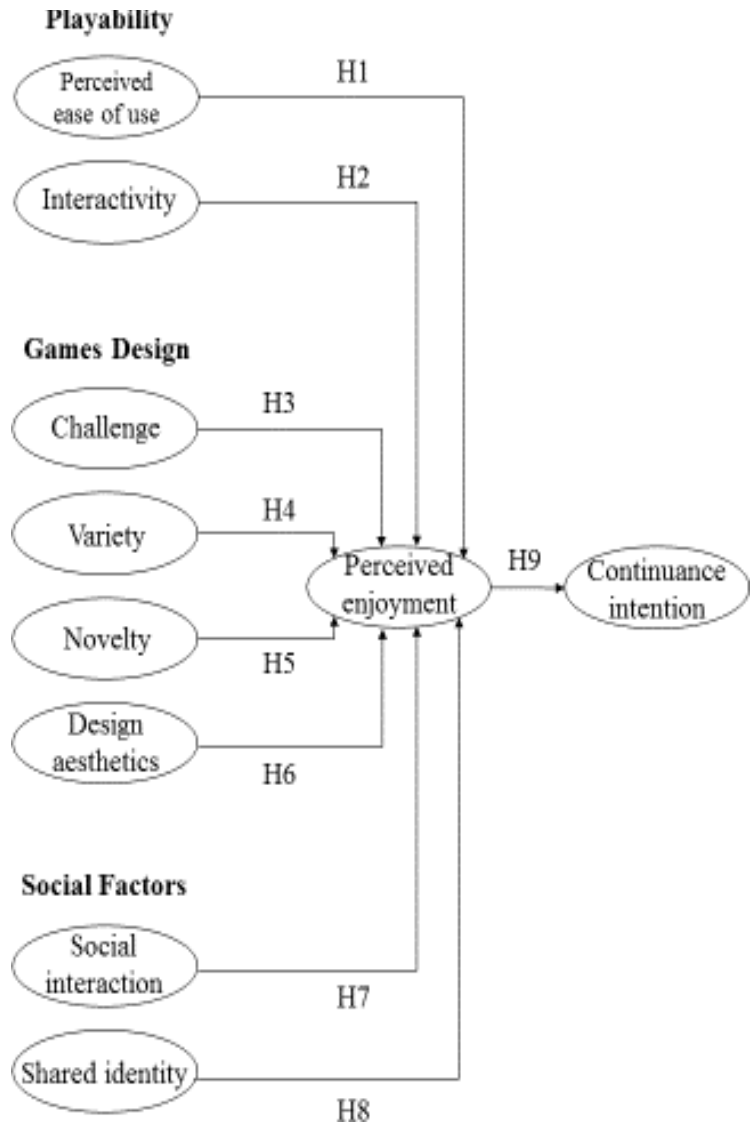

Fig. 1. Research Model

perceived ease of use and enjoyment has been done in empirical studies in mobile and games context [15], [16].

As mobile games are played simultaneously in short time sessions while someone on trips or other activities, it is suggested that perception ease of use has an important role in contributing to an interesting mobile games experience [11]. Based on the above explanation, the proposed hypothesis is:

(H1). Perceived ease of use has a positive relationship and significantly influence perceived enjoyment of mobile games users.

\section{a) Interactivy}

Interactivity refers to the response of a mobile games performance that experienced by its users [17]. Since mobile games are usually played casually in short time intervals, it is 
very important for the users that their mobile games can start, delay, stop or reload quickly [11]. Therefore, the second hypothesis proposed is:

(H2). Interactivity has a positive relationship and significantly influence perceived enjoyment of mobile games users.

\section{2) Games Design Attributes}

\section{a) Challenge}

The challenge is a construction in the games model [18] that defined as the sense of ability of a person being tested [19]. Challenges aren't separated in the context of games where mobile games usually present a series of challenges to be completed by users who have a goal to reach their needs before they can proceed to the next level. However, if the challenge is considered too easy or difficult to resolve, users usually will tend to lose interest in playing [11]. Based on the argument, the proposed hypothesis is:

(H3). Challenge has a positive relationship and significantly influence perceived enjoyment of mobile games users.

\section{b) Variety and Novelty}

Variety exist with the goal of nurturing individual desires and being used as stimulation [20], which is refers to the extent to of users believe that the games to vary in various conditions [21]. If mobile games do not have varying content, then gradually the user will lose interest in playing.

The importance of variety is often associated with novelty, the rate at which games can regenerate on their own. Novelty of mobile games refers to the user feeling for finds something that surprising or different from the previous ones [22]. Therefore, the fourth and forth hypotheses are proposed:

(H4). Variety has a positive relationship and significantly influence perceived enjoyment of mobile games users

(H5). Novelty has a positive relationship and significantly influence perceived enjoyment of mobile games users

\section{c) Design Aesthetic}

Design aesthetic is defined as the balance, emotional appeal, or esthetics of mobile games [15]. According to research conducted by Information Solutions Group (2011), mobile games users claim that improvements in aesthetic graphics design that exist in games affect their experience in playing games [11]. Therefore, the sixth hypothesis proposed is:

(H6). Design aesthetic has a positive relationship and significantly influence perceived enjoyment of mobile games users

\section{3) Social Factors Attributes}

\section{a) Social Interaction}

Social interaction refers to the interaction between two or more users. In the game, users want to interact with friends and maintain their social connections through mobile games. From the perspective of games, interaction is considered one of the most important aspects to experience in playing optimal mobile games [23].
Social interactions in games include expressions of encouragement, excitement, frustration, exchange of strategies and tips about games. Such interactions have a profound impact on pleasure in games because there is a series of interactions in either narrative or storytelling used to build experience of playing [24]. Chang (2012) also shows that the user's enjoyment can come from interactions with others. Based on this explanation, the seventh hypothesis is proposed

(H7). Social interaction has a positive relationship and significantly influence perceived enjoyment of mobile games users

\section{b) Shared Identity}

TABLE I. CONVERGENT VALIDITY

\begin{tabular}{|c|c|}
\cline { 2 - 2 } \multicolumn{1}{c|}{} & Average Variant Extracted \\
\hline PEOU & 0.718 \\
\hline I & 0.643 \\
\hline C & 0.581 \\
\hline V & 0.681 \\
\hline N & 0.520 \\
\hline DE & 0.642 \\
\hline SOI & 0.684 \\
\hline SHI & 0.628 \\
\hline PE & 0.755 \\
\hline CI & 0.806 \\
\hline
\end{tabular}

The majority of games users play with people they know like friends, family, and co-workers [25]. This characteristic results in the user's belief that all their friends have game accounts so they will not feel isolated, and share their identities together [26]. Playing with friends is considered more fun than playing with strangers [27]. Based on this, the eighth hypothesis proposed is:

(H8). Social interaction has a positive relationship and significantly influence perceived enjoyment of mobile games users

4) Perceived Enjoyment and Continuance Intention

Based on the theoretical arguments and key ideas that have been put forward, perceived enjoyment encourage the user to continue playing mobile games. Therefore, researchers want to know whether the perceived enjoyment is encouraging the intention to continue playing mobile games or not:

(H9). Perceived enjoyment has a positive relationship and significantly influence continuance intention of mobile games users

\section{RESULTS}

\section{A. Research Design and Data Collection}

This study was conducted by collecting primary data by spreading questionnaires directly and online, where respondents choose to participate into the survey voluntary. 
Since respondents target were mobile gamers, most of them were easily reachable using online channels. The survey was open from four weeks during March and April 2018. In addition to the quantitative measure, this study also applied maximum likelihood estimator where there must be 5 respondent/observed variable to fulfill requirement adequacy of data [28]. The study itself was conducted in Indonesia, mostly in Jabodetabek region.

\section{B. Sample and data analysis}

In total there were 264 respondents which is fill the survey. Out of these, 215 respondents were received, yielding a response rate of $81.4 \%$. To ensure quality and relevance of the data set, 10 responses were removed because failed the attention traps. As a result, the final sample comprised of 205 responses. The sample is free fromnon-response bias.

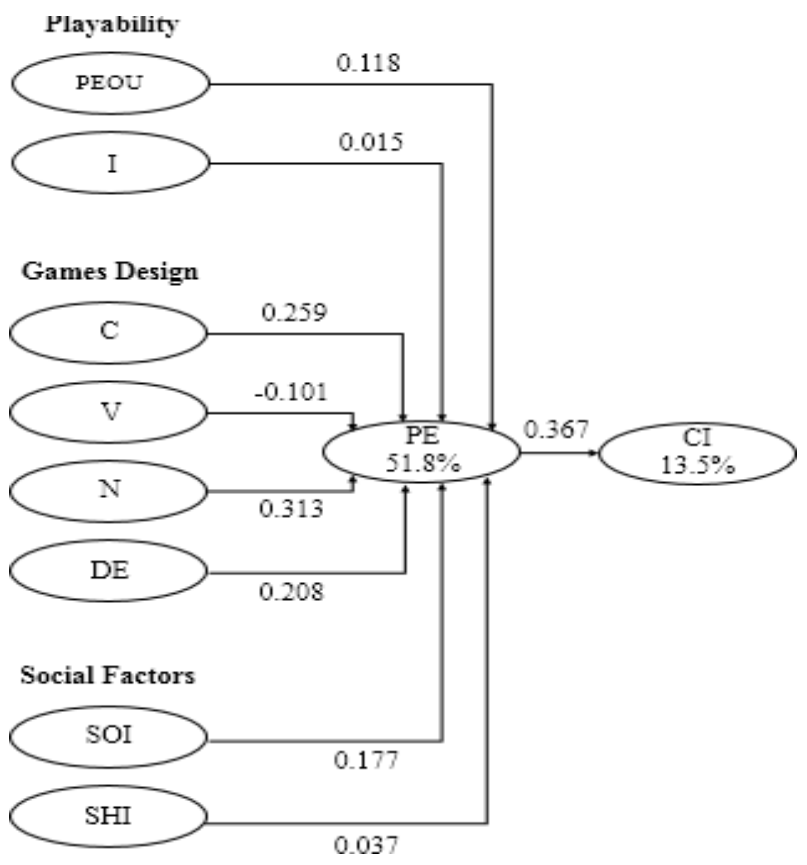

Fig. 2. Estimation Model

When the requirement instrument has been fulfilled, the data was analyzed by using partial-least square structural equation modeling (PLS SEM) with SmartPLS software.

\section{Measurement Model and Structural Model}

There were two estimations in this study to be analyzed which is estimation of measurement model and estimation of structural model. In estimation of measurement model, there are three valuations such as internal consistency reliability, convergent validity and discriminant validity. Meanwhile, in estimation of structural model there are four valuations that be conducted which is multicollinearity model assessment, significance and relevance assessment, coefficients of determination $\left(\mathrm{R}^{2}\right)$ and effect size $\mathrm{f}^{2}[13]$.

Estimation of measurement model was conducted to find out how well the indicators used to measure latent variables. The first assessment is internal consistency reliability. This assessment is done to measure reliability indicator consistency and accuracy of a variable in model by. This assessment can be seen based on composite reliability value whose value should be $\geqslant 0.7$ and Cronbach's Alpha whose.

\begin{tabular}{|c|c|c|}
\cline { 2 - 3 } \multicolumn{1}{c|}{} & TABLE II. & INTERNAL CONSISTENCY RELIABILITY \\
\cline { 2 - 3 } \multicolumn{1}{c|}{} & Composite Reliability & Cronbach's Alpha \\
\hline PEOU & 0.910 & 0.870 \\
\hline I & 0.841 & 0.731 \\
\hline C & 0.874 & 0.819 \\
\hline V & 0.865 & 0.768 \\
\hline N & 0.843 & 0.776 \\
\hline DE & 0.876 & 0.812 \\
\hline SOI & 0.866 & 0.789 \\
\hline SHI & 0.835 & 0.712 \\
\hline PE & 0.925 & 0.892 \\
\hline CI & 0.943 & 0.920 \\
\hline
\end{tabular}

value should be $\geqslant 0.6$ [29], [30]. If both of these values are met, then a variable can be said to be consistent and reliable. It can be seen that each variable has a value of $C R \geqslant 0.7$ and Cronbach's Alpha $\geqslant 0.6$. Therefore, the variable can be said to be consistent and reliable. Internal consistency reliability this research can be seen in Table 1 .

The second assessment of estimation of measurement model is assessment of convergent validity which measured by the average variant extracted (AVE). The variable can be said valid in describing the correlation between the indicator and the latent variable if the value of AVE $>0.5$ [31]. 'Based on the table each of the existing variables are said to be valid because it shows the value of AVE $>0.5$. Convergent validity on this study can be seen in Table 2 .

The last assessment of estimation of measurement model is discriminant validity. This measurement ensures that the indicators in each construct can represent the construct [31],

[32] assessed on the basis of cross loading whose value should be $\geqslant 0.5$ [33]. Discriminant validity of this study be seen in Table 3.

After estimation of measurement model has been done, the next process is estimation of structural model. The first 
TABLE III.

DISCRIMINANT VALIDITY

\begin{tabular}{|c|c|}
\hline & Cross Loading Value \\
\hline PEOU1 & 0.836 \\
\hline PEOU2 & 0.851 \\
\hline PEOU3 & 0.867 \\
\hline PEOU4 & 0.834 \\
\hline I1 & 0.639 \\
\hline $\mathrm{I} 2$ & 0.885 \\
\hline $\mathrm{I} 3$ & 0.858 \\
\hline $\mathrm{C} 1$ & 0.767 \\
\hline $\mathrm{C} 2$ & 0.794 \\
\hline $\mathrm{C} 3$ & 0.836 \\
\hline $\mathrm{C} 4$ & 0.695 \\
\hline $\mathrm{C} 5$ & 0.711 \\
\hline V1 & 0.817 \\
\hline $\mathrm{V} 2$ & 0.854 \\
\hline V3 & 0.803 \\
\hline N1 & 0.607 \\
\hline N2 & 0.665 \\
\hline N3 & 0.780 \\
\hline N4 & 0.738 \\
\hline N5 & 0.799 \\
\hline DE1 & 0.657 \\
\hline DE2 & 0.827 \\
\hline DE3 & 0.867 \\
\hline DE4 & 0.836 \\
\hline SOI1 & 0.756 \\
\hline SOI2 & 0.827 \\
\hline SOI3 & 0.893 \\
\hline SHI1 & 0.736 \\
\hline SHI2 & 0.812 \\
\hline SHI3 & 0.827 \\
\hline PE1 & 0.868 \\
\hline PE2 & 0.665 \\
\hline PE3 & 0.862 \\
\hline PE4 & 0.834 \\
\hline CI1 & 0.869 \\
\hline CI2 & 0.896 \\
\hline $\mathrm{CI} 3$ & 0.904 \\
\hline CI4 & 0.922 \\
\hline
\end{tabular}

TABLE IV. EFFECT Size F² VALUE

\begin{tabular}{|c|c|}
\cline { 2 - 2 } \multicolumn{1}{c|}{} & Effect Size f $^{\mathbf{2}}$ \\
\hline $\mathrm{PEOU} \rightarrow \mathrm{PE}$ & 0.0228 \\
\hline $\mathrm{I} \rightarrow \mathrm{PE}$ & 0.0003 \\
\hline $\mathrm{C} \rightarrow \mathrm{PE}$ & 0.1095 \\
\hline $\mathrm{N} \rightarrow \mathrm{PE}$ & 0.1228 \\
\hline $\mathrm{V} \rightarrow \mathrm{PE}$ & 0.0160 \\
\hline $\mathrm{DE} \rightarrow \mathrm{PE}$ & 0.0584 \\
\hline $\mathrm{SOI} \rightarrow \mathrm{PE}$ & 0.0450 \\
\hline $\mathrm{SHI} \rightarrow \mathrm{PE}$ & 0.0018 \\
\hline $\mathrm{PE} \rightarrow \mathrm{CI}$ & 0.1556 \\
\hline
\end{tabular}

assessment of estimation of structural model is multicollinearity model assessment which can be done by observed variant inflation factor (VIF) value. The research model should not have multicollinearity because if it has multicollinearity then it's indicates that there is an excess indicator [34]. VIF value of each construct should be $<3.30$ [35]. Variant inflation factor (VIF) value can be seen in Table 4.

The next assessment is to measure the significance and relevance which gained from the bootstrapping results in SmartPLS. The value obtained from this process is value tvalue which is stated significant if $>1.96$ and $p$-value which is stated significant if $<0.05$ [13], [28]. Table 5 shows the tvalue and $\mathrm{p}$-value on each construct.

As we can see from the Table 5 we can conclude that perceived ease of use (PEOU), challenge $(\mathrm{C})$, novelty $(\mathrm{N})$, design aesthetic (DE) and social interaction (SOI) have positive relationship and significantly influence perceived enjoyment variables and perceived enjoyment itself have positive relationship and significantly influence continuance intention because all of them have t-value $>1.96$ and $p$-value $<$ 0.05 .

The third assessment on the measurement of the structural model is to assess the coefficient of determination $\left(\mathrm{R}^{2}\right)$. This value is predictive value measure that calculated based on the quadratic correlation between the original value and the predictive value of a particular endogenous construct [28]. Coefficient of determination $\left(\mathrm{R}^{2}\right)$ can be seen on estimation model which is showed in figure 2 .

As we can see in figure 2, PE variable has a value 0.518 and CI has a value 0.135 . This indicates that the variables

TABLE V. VARIANT INFLATION FACTOR VALUE

\begin{tabular}{|c|c|c|}
\cline { 2 - 3 } \multicolumn{1}{c|}{} & PE & CI \\
\hline PEOU & 1.275 & \\
\hline $\mathrm{I}$ & 1.232 & \\
\hline $\mathrm{C}$ & 1.274 & \\
\hline $\mathrm{V}$ & 1.317 & \\
\hline $\mathrm{N}$ & 1.651 & \\
\hline $\mathrm{DE}$ & 1.539 & \\
\hline SOI & 1.466 & \\
\hline SHI & 1.466 & \\
\hline PE & & 1.000 \\
\hline
\end{tabular}

affecting PE can explain by $51.8 \%$ and $\mathrm{PE}$ itself can explain CI by $13.5 \%$. But the value of $\mathrm{R}^{2}$ itself has no rules because this value is highly dependent on the complexity of the model and certain disciplines. A value of 0.20 in $\mathrm{R}^{2}$ is considered high in behavioral studies. Additionally, adding additional insignificant constructs to explain endogenous latent variables will affect the value of $R^{2}[13]$.

The last assessment is measurement of effect size $\mathrm{f}^{2}$. This value represents a change from the value of $\mathrm{R}^{2}$ in certain exogenous constructs omitted from the model that can be used to evaluate the omitted constructs either will have an impact or not. Table 6 is the value of effect size $\mathrm{f}^{2}$ in each construct. According to Cohen (1988), the effect size $\mathrm{f} 2$ with a value of 
0.02 indicates a weak effect, the value 0.15 indicates a moderate effect and a value of 0.35 indicates a large effect [36].

\section{DISCUSSIONS}

\section{A. Findings}

From the research result, we found that there are five exogenous constructs that influence perceived enjoyment, there are perceived ease of use, challenge, novelty, aesthetics design and social interaction in mobile games. We find out too that intentions to continue playing mobile games are strongly driven by perceived enjoyment where primarily sponsored by novelty of mobile games, challenge which exists in mobile game and attractive visual of mobile games. We also prove that social factors, which is social interaction has driven enjoyment too. Yet social interaction and perceived ease of use are still relevant, but in moderate influence. So, from this finding we suggest to developers of mobile games should focus on these factors.

This finding also strengthens J. Merikivi et al. research that enjoyment has a direct and effective influence on continued mobile gaming lends support to the hedonistic paradigm in technology adoption research [37]. From their research, perceived ease of use, challenge, novelty and design aesthetic as elements that driven the enjoyment, which perceived ease of use is the element which most affected the enjoyment.

From the results of our analysis confirmed that role of novelty, challenge and design aesthetic as determinants of perceived enjoyment. Novelty of mobile games and challenge, which is more related to the game design factors, indicates that new features and progressions of task difficulty can maintain users' enjoyment. As for most users, if mobile

\begin{tabular}{|c|c|c|}
\multicolumn{1}{c|}{} & TABLE VI. & \multicolumn{2}{c|}{ T-VALUE AND P-VALUE } \\
\cline { 2 - 3 } \multicolumn{1}{c|}{} & t-value & p-value \\
\hline $\mathrm{PEOU} \rightarrow \mathrm{PE}$ & 2.077 & 0.038 \\
\hline $\mathrm{I} \rightarrow \mathrm{PE}$ & 0.223 & 0.824 \\
\hline $\mathrm{C} \rightarrow \mathrm{PE}$ & 4.291 & 0.000 \\
\hline $\mathrm{N} \rightarrow \mathrm{PE}$ & 5.201 & 0.000 \\
\hline $\mathrm{V} \rightarrow \mathrm{PE}$ & 1.780 & 0.074 \\
\hline $\mathrm{DE} \rightarrow \mathrm{PE}$ & 3.004 & 0.003 \\
\hline $\mathrm{SOI} \rightarrow \mathrm{PE}$ & 2.949 & 0.003 \\
\hline $\mathrm{SHI} \rightarrow \mathrm{PE}$ & 0.628 & 0.531 \\
\hline $\mathrm{PE} \rightarrow \mathrm{CI}$ & 5.614 & 0.000 \\
\hline
\end{tabular}

games fails to arouse their curiosity, it would leave users bored and distressed [11]. Moreover, mobile games has played on mobile devices with small screens of different sizes, interfaces design have be crucial issues. This is line with studies on internet websites (van der Heijden, 2003) and mobile websites [15] that found interface design to play a central role in enjoyment experienced for users.

An empirical example of mobile games that have successfully implemented these variables is Mobile Legend from publisher Moontoon. In the perceived ease of use variable, Mobile Legend is easy to use even for users who have never played similar games because have simple gameplay and have many tutorials when it is use for first time on this game like how to attack the enemy, move the character and using character skill. In addition, the control of the game is also fairly easy because it has a virtual feature on, so users can easily control the character to move, attack or use the skill without having to move the finger towards to the enemy because there is also an auto-aim feature in the virtual pad that automatically set movement for user's character.

For the challenge variable, Mobile Legend have daily tasks that can be easily solved by the users. In addition, there are also more difficult tasks based from degree of the user. Higher user rank generates in harder tasks and enemies that the user will be face.

For the novelty variable, Mobile Legend is the first mobile games in Massive Online Battle Arena (MOBA) category. This game adopts PC games Dota 2, but with smaller and mobile versions. The overall aspect of the Mobile Legend game is similar but much easier to play than Dota 2. In addition, there are also some characters that represent some countries as part of the localization and marketing strategies.

For the aesthetic design variables, Mobile Legend have good terms in characters, maps, items, effects skill and many more. Movement of its character was not stiff too when attacking the enemy. For the last element that is social interaction, in Mobile Legend game user can communicate by using chat feature or voice chat either with friend from user or enemy when in games.

In addition, based on data obtained, most mobile games users are in the age of range 15 to 25 years. This indicates that mobile games users included into the category of generation $Z$. Generation $Z$ is a generation when the digital world began to penetrate and grow rapidly. Generation $Z$ is also very adept at using technology in all aspects. However, generation $\mathrm{Z}$ is also easy to bend tend to something. When we associated with mobile games, if mobile games do not give them a sense of pleasure, of course they will leave the mobile games. Therefore, user experience and factors such as perceived ease of use, challenge, novelty, aesthetics design and social interaction that affect perceived enjoyment play an important role in mobile games.

Considering statement above, it is important for developers to accommodate and ensure that mobile games users get the value and experience they expect when using mobile games. Long and fun first experience when using mobile games can be a solution for mobile games developers to make their users interested and motivated to use mobile games and have the intention to re-use the mobile games in the next sessions.

\section{B. Research Implication}

This research has implications on two aspects, theoretically and managerially. Theoretically, this research proves that perceived enjoyment factor has strong relationship and influence continuance intention in mobile games users which is obtained based on causal analysis and hypothesis analysis. 
Journal of Games, Game Art and Gamification Vol. 05, No. 01, 2020

Special Issues: 2018 International Conference of Games, Game Art and Gamification

While on the managerial aspect, this research can be one of the inputs for mobile game developers in developing mobile games that can be accepted by mobile games users by taking into account the significant factors that exist in this research in order to avoid failure in maintaining continuance intention that happened at currently.

\section{Limitations and future research}

Although this study makes several contributions to understanding of perceived enjoyment in mobile games, there are limitation need to be noted. The first one that to be noted that this study is not focused and specific to one particular type of mobile games. In addition, because mobile games have a large number of categories and numbers, it is difficult to give a specific and strong recommendation. This study also intended to provide an overview and input for mobile game developers. However, the input provided is still a general, not a technical and specific recommendation so that the research needs to be focused on specific issues for further development.

Thus, for the next future research we propose that the research must focus on specific mobile games to provide technical and specific recommendation. It can also be done using other research models and other factors that may affect continuance intention and be done in different geographical areas to obtain comparison of analytical results in different geographic areas. As for relevant stakeholders such as mobile games developers, should pay attention to the factors that affect the user's feelings of pleasure, especially factors that affect the user experience in playing games.

\section{CONCLUSION}

It is known that perceived enjoyment is influenced by perceived ease of use, challenge, novelty, aesthetic design and social interaction factors. In addition, it is evident that this perceived enjoyment affects continuance intention. The findings of this study confirm that perceived enjoyment does have an effective direct effect on the perspective of mobile games users to continue to have intentions in playing mobile games. Users of mobile games also have no obvious external motive except to feel the pleasure when they play mobile games.

In addition, based on data we got, most of mobile games users are generation $\mathrm{Z}$ which is very adept to use technology in all aspects. However, this generation is easy to bend tend of something so when they feels dissatisfied with mobile games they will remove it. Considering for this issues, it's important for developers to accommodate and ensure that their mobile games get the value and experience what they expect when using it. Long and fun first experience with considering perceived ease of use, challenge, novelty, aesthetic design and social interaction factors can be a solution for developers to make their users interested and motivated to use their mobile games. That is, perceived enjoyment is a powerful motive that makes the user decide tocontinue using mobile games.

\section{ACKNOWLEDGMENT}

This research is affiliated with University of Indonesia and funded by research grant from University of Indonesia (Hibah Riset PITTA).

\section{REFERENCES}

[1] S. Millward, "Indonesia to be world's fourth-largest smartphone market by 2018," $2014 . \quad$ [Online]. Available: https://www.techinasia.com/indonesia-worlds-fourth-largestsmartphone-2018-surpass-100-million-users.

[2] C. Janssen, "Definition - What does Mobile Application mean," unpublished.

[3] I. Setiawan, "Baidu-GFK: Pendapatan Mobile Apps Diprediksi CapaiUS\$142,1 Juta," 2016. [Online]. Available: https://swa.co.id/swa/trends/business-research/baidu-gfk-pendapatanmobile-apps-diprediksi-capai-us-1421-juta-di-2016.

[4] S. Perez, "App Store to Reach 5 Millions Apps by 2020," 2016. [Online]. Available: https://techcrunch.com/2016/08/10/app-store-toreach-5-million-apps-by-2020-with-games-leading-the-way/.

[5] M. Amstrong, "The Companies Making The Most From Video Games," $2017 . \quad$ [Online]. Available: https://www.statista.com/chart/8870/tencent-is-top-of-the-gamerevenues-leaderboard/.

[6] E. McDonald, "The Global Games Market Will Reach \$108.9 Billion in 2017 With Mobile Taking 42\%," 2017. [Online]. Available: https://newzoo.com/insights/articles/the-global-gamesmarket-will- reach-108-9-billion-in-2017-with-mobile-taking-42/.

[7] S. Unity, "Can't stop, won't stop: 2016 mobile game and VR games year in review," Drug and Therapeutics Bulletin, vol. 53, no. 12, p. 133, 2015.

[8] Adjust, "Birth, life and death of an app - a look at the apple app store in July 2014," 2014. [Online]. Available: https://www.adjust.com/assets/downloads/\%0AAppleAppStore_Rep ort2014.pdf.

[9] N. Purcell, K., Entner, R., \& Henderson, "The rise of apps culture," $2010 . \quad$ [Online]. Available: http://www.pewinternet.org/2010/09/14/the-rise-of-apps-culture/.

[10] J. Brightman, "Player Retention Is The Key To Success," GamesIndustry International, 2014. [Online]. Available: https://www.gamesindustry.biz/articles/2014-03-11-player-retentionis-the-key-to-success-steve-nix.

[11] J. Merikivi, V. Tuunainen, and D. Nguyen, "What makes continued mobile gaming enjoyable?," Comput. Human Behav., vol. 68, pp. 411-421, 2017.

[12] A. Chen, Y. Lu, B. Wang, and A. Chen, "Enhancing perceived enjoyment in social games through social and gaming factors," 2016.

[13] J. F. J. Hair, G. T. M. Hult, C. Ringle, and M. Sarstedt, A Primer on Partial Least Squares Structural Equation Modeling (PLS-SEM), vol. 46, no. 1-2. 2014.

[14] F. D. Davis, "User Acceptance of Computer Technology: A Comparison of Two Theoretical Models User Acceptance Of Computer Technology: A Comparison Of Two," no. September 2016, 1989.

[15] D. Cyr, M. Head, and A. Ivanov, "Design aesthetics leading to mloyalty in mobile commerce $\S, "$ vol. 43, pp. 950-963, 2006.

[16] H. Hsu, C., Lu, H., \& Hsu, "Adoption of the mobile internet: An empirical study of multimedia message service (MMS)," Omega, vol. 35, no. 6, pp. 715-726, 2007.

[17] T. P. Novak, D. L. Hoffman, Y. Yung, T. P. Novak, and D. L. Hoffman, "Approach Linked references are available on JSTOR for this article: Measuring the Customer Experience in Online Environments : A Structural Modeling Approach," vol. 19, no. 1, pp. 22-42, 2000.

[18] C. Crawford, Chris Crawford on game design. Indianapolis, IN: New Riders, 2003.

[19] R. Bridges, E., \& Florsheim, "Hedonic and utilitarian shopping goals: The online experience," J. Bus. Res., vol. 61, no. 4, pp. 309314, 2008.

[20] D. E. Berlyne, Conflict, arousal, and curiosity. New York, NY: McGraw-Hill, 1960. 
[21] F. B. Chung, J., \& Tan, "Antecedents of perceived playfulness: An exploratory study on user acceptance of general informationsearching websites," Inf. Manag., vol. 41, no. 7, pp. 869-881, 2004.

[22] M. Huang, "Designing website attributes to induce experiential encounters," Comput. Human Behav., vol. 19, no. 4, pp. 425-442, 2003.

[23] C. C. Chang, "Examining users' intention to continue using social network games: a flow experience perspective," Telemat. Informatics,vol. 30, no. 4, pp. 311-321, 2012.

[24] J. Choi, D. and Kim, "Why people continue to play online games: in search of critical design factors to increase customer loyalty to online contents," Cyber Psychol. Behav., vol. 7, no. 1, pp. 11-24, 2004.

[25] D. Y. Lee, Y.-H. and Wohn, "Are there cultural differences in how we play? Examining cultural effects on playing social network games," Comput. Human Behav., vol. 28, no. 4, pp. 1307-1314, 2012.

[26] J. Hou, "Uses and gratifications of social games: blending social networking and game play," First Monday, vol. 16, no. 7, pp. 5-15, 2011.

[27] J. Paavilainen, J., Hamari, J., Stenros, J. and Kinnunen, "Social network games: players' perspectives," Simul. Gaming, vol. 46, no. 6,pp. 794-820, 2013.

[28] S. H. Wijanto, Structural Equation Modeling dengan LISREL 8.8

Yogyakarta: Graha Ilmu, 2008.
[29] I. Meilani, Y. F., Lemy, D. M., \& Bernarto, "Local Young Tourists' Perceptiions of Service Quality, Motivation, Satisfaction and Loyalty in Choosing Dunia Fantasi (DUFAN) as Tourist Attraction," 2013 Int.Conf. Business, Econ. Account., pp. 1-15, 2013.

[30] S. M. Mackey, A., \& Gass, "Second language research: Methodology and," Routledge, 2013.

[31] J. F. J. Hair, Multivariate data analysis: A global perspective, 7th ed. New York: Pearson, 2010.

[32] M. Henseler, J., Ringle, C. M., \& Sarstedt, "A New Criterion for Assessing Discriminant Validity in Variance-based Structural Equation Modeling," J. Acad. Mark. Sci., pp. 115-135, 2015.

[33] I. Jaya, I. M., \& Sumertajaya, "Permodelan Persamaan Struktural dengan Partial Least Square," Semnas Mat. dan Pendidik. Mat., pp. $118-132,2008$

[34] F. Peng, D. X., \& Lai, "Using Partial Least Squares in Operations Management Research: A Practical Guideline and Summary of Past Research," J. Oper. Manag., pp. 467-480, 2012.

[35] A. and J. A. S. Diamantopoulos, "Formative Versus Reflective Indicators in Organizational Measure Development: A Comparison and Empirical Illustration,” Br. J. Manag., pp. 263-282, 2006.

[36] J. Cohen, Statistical power analysis for the behavioral sciences. Mahwah, NJ: Lawrence Erlbaum, 1988.

[37] H. van der Heijden, "User acceptance of hedonic information systems," MIS Q., vol. 28, no. 4, pp. 695-704, 2004. 